\title{
НОВЫЕ ИНСТРУМЕНТЫ БЕЗНАЛИЧНЫХ РАСЧЕТОВ: СПЕЦИАЛЬНЫЕ БАНКОВСКИЕ СЧЕТА
}

\author{
А. В. Прокофьев ${ }^{1}$, В. А. Татьянников ${ }^{2}$, Е. Н. Прокофьева 2 \\ 1 Публичное акционерное общество «ВТБ», г. Екатеринбург, Российская Федерация \\ 2 Уральский государственный экономический университет, г. Екатеринбург, Российская Федерация
}

Информация о статье

Дата поступления

4 мая 2017 г.

Дата принятия к печати

14 июня 2017 г.

Дата онлайн-размещения 15 сентября 2017 г.

\section{Ключевые слова}

Финансовый инструмент; номинальный счет; счет-эскроу; бенефициар; минимизация рисков

\begin{abstract}
Аннотация
Характер развития системы безналичных расчетов в России свидетельствует о максимизации их доли в недалеком будущем. Безналичные расчеты не только позволяют повысить скорость перевода и эфрфективность использования денежных средств, они также призваны минимизировать риски самих участников расчетов. В соответствии с такой тенденцией определяют специфику своей деятельности и коммерческие банки. Именно они в жесткой конкурентной среде стремятся обеспечить наилучшие условия не только по скорости, ликвидности и безопасности расчетов, но и повысить разнообразие предлагаемых продуктов и услуг. В статье исследуются современные особенности развития банковской системы и определяется круг фракторов, оказывающих влияние на политику банков при организации безналичных расчетов. Обосновывается авторское видение характера функционирования банков как основных участников системы безналичных расчетов, определяются их характерные черты и возможные конкурентные преимущества в данной сфере. Кроме того, в работе рассматриваются новые банковские продукты, предлагаемые в области безналичных расчетов, целью использования которых является повышение безопасности движения денежных средств.
\end{abstract}

\section{NEW INSTRUMENTS OF NON-CASH PAYMENTS: SPECIAL BANK ACCOUNTS}

\author{
Alexander V. Prokofiev', Vasily A. Tatyannikov², Elena N. Prokofieva ${ }^{2}$ \\ 1 Public JSC "VTB", Yekaterinburg, Russian Federation \\ ${ }^{2}$ Ural State University of Economics, Yekaterinburg, Russian Federation
}

\author{
Article info \\ Received \\ May 4, 2017 \\ Accepted \\ June 14, 2017 \\ Available online \\ September 15, 2017

\section{Keywords} \\ Financial instrument; nominal \\ account; escrow account; \\ beneficiary; risk minimization
}

\begin{abstract}
The nature of the development of cashless payments in Russia testifies to maximize their share in the near future. Non-cash payments not only allow you to increase the speed of translation and the efficiency of use of funds, they are also designed to minimize the risks of participants in the calculations. Commercial banks build their work in accordance with this trend. In a tough competitive environment they strive to provide the best conditions not only for speed, liquidity and safety of payments, but also the variety of the offered products and services in the field of cashless payments. The article examines the trends in the development of the banking system and establishes the range of factors that influence the policy of the banks in organization of cashless settlements. The authors ground their vision of the nature of functioning of banks as the main participants of the cashless payment systems; they also define their character features and potential competitive advantages in this sphere. The article is also dedicated to new banking products offered in the cashless payment systems that are aimed to increase the security of cash flow.
\end{abstract}

Современная система безналичных расчетов основывается на взаимосвязи и взаимозависимости деятельности трех участников: Центрального банка, коммерческих банков и клиентов (юридических и физических лиц) [1].
Политика Центрального банка в последние 20-25 лет была ориентирована на рост доли безналичных расчетов. Отказ от бумажных технологий и максимизация безналичных расчетов с использованием электрон- 
ных денег позволяют повысить прозрачность платежей. Особо следует отметить, что государство получает дополнительные преимущества: во-первых, происходит сокращение расходов на выпуск денег; во-вторых, возможно появление определенного эфрфекта от использования средств, находящихся на соответствующих счетах в банках для кредитования реального сектора экономики, что является дополнительным основанием для повышения темпов экономического роста.

Непосредственной реализацией целей и задач Центрального банка занимаются коммерческие банки. Отдельные действия как банков, так и клиентов, участвующих в расчетах, строго регламентирована соответствующими законодательно-нормативными актами, а другие действия относятся к рыночной сорере. Для юридических лиц регулируемыми процессами являются:

- регламентация порядка расчета лимита кассы;

- обязательность осуществления значительного объема платежей в безналичной форме;

- определение максимальной суммы платежа, осуществляемого наличными средствами;

- регламентация форм безналичных расчетов и порядка их использования и т. д.

Физические лица имеют большую свободу в использовании наличных средств и организации расчетов в целом.

К рыночной сорере могут быть отнесены действия банка в области политики по расчетно-кассовому обслуживанию клиентов, такие, например, как установление величины комиссий и тарифов, составление перечня открываемых счетов и определение характера использования каналов перевода денежных средств, разработка техники и технологии обслуживания клиентов.

Цель исследования, проведенного в рамках статьи, состоит в систематизации теоретических и практических данных, касающихся организации безналичных расчетов коммерческими банками для выявления и обоснования перспективных направлений их развития.

Характер работы определили следующие задачи:

- рассмотреть тенденции развития денежного обращения в России в целом и безналичных расчетов в частности;

- оценить специфику деятельности коммерческих банков с учетом происходящих изменений;

- позиционировать новые банковские продукты в области безналичных расчетов, появившиеся на рынке;
- обосновать необходимость и возможность использования этих продуктов как юридическими, так и физическими лицами.

Банк - один из старейших и наиболее влиятельных институтов денежно-кредитной системы любого цивилизованного государства. В условиях постоянно меняющегося и развивающегося финансового рынка, банки предлагают клиентам все большее количество новых фринансовых инструментов и услуг, в том числе и в рамках классических банковских операций, среди которых традиционными являются кредитование, депозитные операции и организация расчетов. Последние две имеют особое значение. На это обращают внимание такие экономисты, как Г. А. Галимова, З. Р. Абдеева, С. В. Криворучко, В. А. Лопатин, М. А. Абрамова, И. Е. Шакер, Э. С. Чижова, М. А. Герасименко, Р.Н.Деникаева, О. С. Каплина и др. [2-8]. Качественно осуществляя расчетно-кассовое обслуживание, банки получают возможность увеличивать клиентскую базу, а вслед за этим и предлагать клиентам воспользоваться иными услугами банка.

При рассмотрении расчетно-кассового обслуживания клиентов с позиции банка, всегда обращается внимание на то, что данная деятельность обеспечивает ему не только доходность, но и ликвидность $[1 ; 9 ; 10]$. Увеличение клиентской базы способствует росту остатков средств на корреспондентских счетах банка и создает потенциальные возможности для улучшения показателей ликвидности [11, с. 46].

Остатки средств кредитных организаций на корреспондентских счетах в Центральном банке России за 2010-2017 гг. подтверждают это (данные приводятся в млрд р. по состоянию на 1 января каждого года): 2010 г. 900,3; 2011 г. - 994,0; 2012 г. - 981,6; 2013 г. - 1356,$3 ; 2014$ г. - 1 270,0; 2015 г. 1215,5 ; 2016 г. - 1 594,0; 2017 г. - $1822,7^{1}$.

Необходимо обратить внимание на некоторые особенности. Анализируемый период характеризуется разными экономическими и социально-политическими условиями развития страны и мира. Тенденции формирования реального сектора экономики и банковской системы взаимосвязаны и взаимозависимы. Соответственно, рост ликвидности в последние 2-3 года может быть следствием консервативной политики банков по размещению денежных средств из-за значительного сокращения количества надежных заемщиков. Как известно, замедление темпов экономического роста

1 ЦБ РФ статистика. Банковский сектор. URL: http: //www.cbr.ru/statistics/?prtid=pdko. 
неизбежно приводит к сокращению реальных доходов населения и ухудшению показателей финансовой устойчивости хозяйствующих субъектов. Более того, вклады населения во все времена, а в условиях кризиса тем более, относились к неустойчивым пассивам [12, с. 41]. Поэтому наличие возможности оттока денежных средств требует от банка повышения доли ликвидных активов в целом и, в частности, наличия большего объема средств на корреспондентских счетах.

Из сказанного следует вывод, что прямую взаимосвязь между спецификой и качеством организации расчетно-кассового обслуживания клиентов и уровнем остатков средств на корреспондентских счетах банков в современных условиях проводить сложно.

В то же время анализ структуры денежного агрегата M2 показывает наличие положительной динамики, которая проявляется в росте доли безналичных средств в структуре денежного оборота. Это, напротив, может свидетельствовать и о повышении качества, и о росте спроса на услуги банка по организации расчетно-кассового обслуживания (табл. 1).

В представленных данных исключением являются конец 2013 и начало 2014 г. Введение санкций, падение курса национальной валюты, осложнения, связанные с формированием доходной части бюджета, и другие факторы способствовали росту неопределенности в прогнозировании будущего финансового положения как хозяйствующих субъектов, так и физических лиц [13], а это не могло не отразиться на повышении спроса на наличные средства, в том числе и вследствие оттока вкладов из банков.

Одна из основных задач, стоявших перед банками в последние 2-3 года, заключалась в стабилизации ресурсной базы банка. Учитывая, что увеличение количества клиентов в целом, а следовательно, и участников системы безналичных расчетов в условиях незначительного роста экономики маловероятно, предполагается, что банки будут активно бороться за клиентов. Возможность для активизации конкурентной борьбы связана и с сокращением числа коммерческих банков, функционирующих в экономике страны [14]. По состоянию на 1 января 2010 г. на территории России действовало 1007 банков, к 1 января 2017 г. число банков сократилось до 575, а к 1 июля 2017 г. осталось 544 банка².

Такие тенденции могут формировать дополнительные преимущества для банков с государственным участием. В условиях нестабильности главным требованием клиентов, размещающих короткие деньги, является надежность и ликвидность института, предоставляющего услуги, а затем идет величина комиссий и тарифов, скорость расчетов ит. д.

Таким образом, если говорить о конкуренции, в том числе среди лидеров банковского рынка, то основными конкурентными преимуществами будут именно скорость оказания услуги и ее стоимость.

Увеличение скорости расчетов возможно посредством использования современных технологий. Реализовать данную задачу во многом позволяет Интернет. Главное преимущество системы электронных платежей - сокращение операционных издержек. Это обеспечивает не только увеличение доходов банка, но и формирует условия для создания более выгодных предложений для клиентов [3; 7].

Современные технологические возможности меняют характер классической банковской операции:

- увеличивается доля операций, совершаемых удаленно;

- появляются банки, не имеющие отделений;

2 ЦБ РФ статистика. Банковский сектор. URL: http://www.cbr.ru/statistics/?prtid=pdko.

Структура агрегата M2 в 2011-2017 гг., млрд р. *

\begin{tabular}{|l|r|r|r|r|r|r|r|}
\hline \multicolumn{1}{|c|}{ Показатель } & \multicolumn{1}{c|}{2011} & \multicolumn{1}{c|}{2012} & \multicolumn{1}{c|}{2013} & \multicolumn{1}{c|}{2014} & \multicolumn{1}{c|}{2015} & \multicolumn{1}{c|}{2016} & \multicolumn{1}{c|}{2017} \\
\hline Всего & 15267,6 & 20011,9 & 27405,4 & 31404,7 & 32110,5 & 35809,2 & 38417,9 \\
\hline Агрегат МО & 4038,1 & 5062,7 & 6430,1 & 6985,6 & 71717,5 & 7239,1 & 7714,8 \\
\hline Доля наличных средств, \% & 26,45 & 25,30 & 23,47 & 25,49 & 22,34 & 20,22 & 20,08 \\
\hline Безналичные средства & 11229,5 & 14949,1 & 20975,3 & 24419,1 & 24939,1 & 28570,1 & 30703,1 \\
\hline Доля безналичных средств, \% & 73,55 & 74,70 & 76,53 & 74,51 & 77,66 & 79,78 & 79,92 \\
\hline
\end{tabular}

* Составлена по данным Центрального банка России. URL: http://www.cbr.ru/statistics/?prtid=pdko. Данные приведены по состоянию на 1 января текущего года. 
- повышается информационная безопасность;

- создаются условия для комплексного обслуживания клиентов, когда клиентам, имеющим расчетные счета, банки предоставляют также кредитные, депозитные, депозитарные и иные услуги (постепенно и данный круг операций будет осуществляться дистанционно);

- появляются условия для роста ликвидности и доходности банка, что обеспечивают не только классические тарифы и комиссии за открытие счета и переводы денежных средств, но и предоставляемые клиентам дополнительные услуги (например, размещение части остатков «коротких денег» в краткосрочные или ликвидные инструменты фринансового рынка).

Конкуренция на финансовом рынке обязывает банки предлагать клиентам новые, интересные продукты и услуги, отвечающие требованиям времени. Такими в сорере расчетно-кассового обслуживания клиентов являются номинальные счета и счета-эскроу. Отечественными экономистами предпринимаются попытки оценить их эфффективность и востребованность на рынке $[2 ; 15 ; 16]$.

В основе своей исследуемые счета не более чем разновидность банковского счета. На них хранятся безналичные денежные средства, с ними совершаются операции, в связи с чем эти счета обладают как общими характеристиками, присущими всем банковским счетам, так и специфическими особенностями.

Номинальный счет отличается тем, что он может открываться для совершения операций с денежными средствами, права на которые принадлежат другому лицу - бенефициару (или нескольким лицам - бенефициарам), если иное не установлено законом. Договор номинального счета может быть заключен как с участием, так и без участия бенефициара. В случае, если на номинальном счете учитываются денежные средства нескольких бенефициаров, средства каждого из них отражаются банком на специальных разделах номинального счета при условии, что в соответствии с законом или договором номинального счета обязанность по учету денежных средств бенефициаров не возложена на владельца счета.

Порядок движения денежных средств и документов при организации расчетов с использованием номинального счета можно представить графически (рис. 1). Он включает шесть этапов:

1. Заключение договора.

2. Открытие счета.

3. Зачисление средств на номинальный счет.

4. Предоставление подтверждающих документов.
5. Согласование платежа.

6. Распоряжение о платеже.

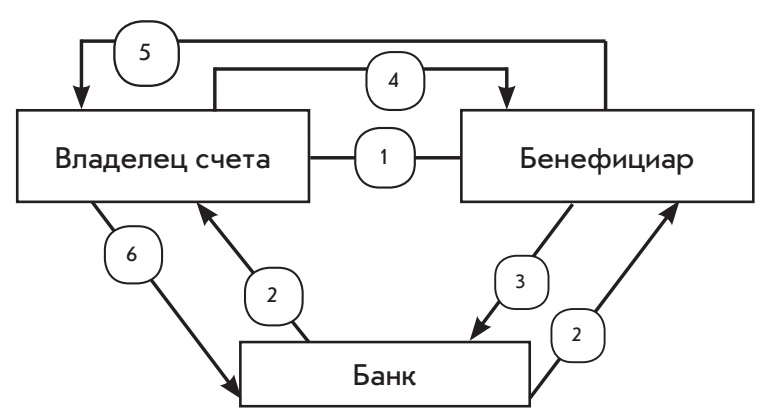

\section{Рис. 1. Схема работы номинального счета}

Договор номинального счета с участием бенефициара может быть изменен или расторгнут только с его согласия, если законом или договором номинального счета не предусмотрено иное. При расторжении такого договора остаток денежных средств перечисляется на другой номинальный счет владельца или выдается бенефициару, либо по указанию бенефициара перечисляется на другой счет.

Таким образом, принципиальные особенности договора номинального счета состоят в том, что он определяет:

- круг лиц, которым могут перечисляться или передаваться денежные средства, а также лиц, с согласия которых могут совершаться операции по счету;

- документы, являющиеся основаниями для совершения операций.

Счета-эскроу открываются в соответствии со ст. 860.7 Гражданского кодекса Рф. Эскроу-агент (банк) открывает специальный счет (эскроу) для учета и блокирования денежных средств, полученных от депонента (владельца счета) в целях их передачи другому лицу (бенефициару) при возникновении оснований, предусмотренных договором между банком, депонентом и бенефициаром. Депонент и бенефициар не имеют права распоряжаться денежными средствами, находящимися на счете-эскроу, если это не оговорено договором.

Зачисление на счет-эскроу иных денежных средств депонента, помимо суммы, указанной в договоре условного депонирования денежных средств, не допускается, если это не предусмотрено договором.

Банк обязан выдать бенефициару депонированную сумму или перечислить ее на указанный им счет при возникновении оснований, предусмотренных договором условного депонирования денежных средств, в установленный срок, а при его отсутствии в течение десяти дней. 
Движение денежных средств и документов при организации расчетов с использованием счета-эскроу производится в определенном порядке (рис. 2) и включает шесть этапов:

1. Заключение договора купли-продажи.

2. Открытие счета-эскроу.

3. Перевод денежных средств.

4. Предоставление документов, подтверждающих переход права собственности.

5. Согласование платежа.

6. Перевод средств.

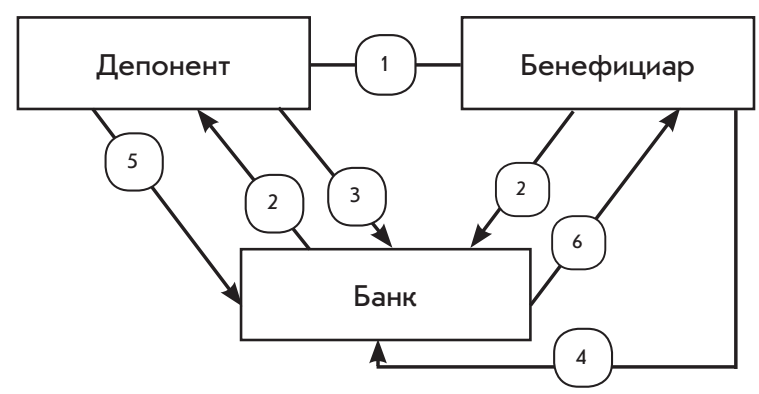

Рис. 2. Схема работы счета-эскроу

Закрытие счета-эскроу осуществляется банком по истечении срока действия договора условного депонирования денежных средств или при условии его прекращения по иным основаниям. Правила, предусмотренные в ст. 859, указывающие на то, что договор банковского счета расторгается по заявлению клиента в любое время, не применяются к счету-эскроу, как и п 2 ст. 859, где говорится о расторжении договора банковского счета по требованию банка.

При расторжении договора счета-эскроу остаток денежных средств перечисляется или выдается депоненту либо, если возникают основания для передачи денежных средств бенефициару, перечисляется или выдается ему.

Применение номинального счета и счета-эскроу целесообразно в операциях, связанных с куплей-продажей материальных (нематериальных) активов, а также в иных сделках инвестиционного характера. Кроме того, они могут быть выгодны клиентам в качестве способа минимизации риска неоплаты контракта или для исключения нецелевого использования денежных средств. Номинальный счет и счет-эскроу обладают определенными схожими характеристиками:

- имеют особый режим ведения, зачисления и использования денежных средств, а также специальные условия закрытия;

- рассматриваются в качестве способа минимизации риска через возложение на банк функций контроля за соблюдением условий договора;

- требуют индивидуального подхода;

- открытие счета и совершение по нему операций обеспечивает банку получение высокого вознаграждения.

Однако кроме сходства данные счета имеют и некоторые различия (табл. 2).

Различия номинального счета и счета-эскроу

\begin{tabular}{|c|c|c|}
\hline Показатель & Номинальный счет & Счет-эскроу \\
\hline $\begin{array}{l}\text { Выдача денежных } \\
\text { средств бенефи- } \\
\text { циару }\end{array}$ & Производится в случае расторжения счета & $\begin{array}{l}\text { Осуществляется при возникновении основа- } \\
\text { ний, предусмотренных договором условного } \\
\text { депонирования денежных средств }\end{array}$ \\
\hline $\begin{array}{l}\text { Предоставление } \\
\text { сведений, } \\
\text { составляющих } \\
\text { банковскую тайну }\end{array}$ & $\begin{array}{l}\text { Предоставляются владельцу счета, а также } \\
\text { бенефициару, если договор заключен с его } \\
\text { участием, либо если такое право предо- } \\
\text { ставляется ему договором, когда договор } \\
\text { заключен без участия бенефициара }\end{array}$ & $\begin{array}{l}\text { Предоставляются как владельцу счета, так и } \\
\text { бенефициару }\end{array}$ \\
\hline $\begin{array}{l}\text { Расторжение } \\
\text { договора }\end{array}$ & $\begin{array}{l}\text { С согласия бенефициара, если договор был } \\
\text { заключен с его участием; если договор } \\
\text { был заключен без участия бенефициара, } \\
\text { то он обязательно информируется банком } \\
\text { о поступлении заявления от владельца о } \\
\text { расторжении договора }\end{array}$ & $\begin{array}{l}\text { Закрытие счета осуществляется банком по } \\
\text { истечении срока действия договора условно- } \\
\text { го депонирования денежных средств или по } \\
\text { иным его основаниям }\end{array}$ \\
\hline $\begin{array}{l}\text { Выдача остатков } \\
\text { денежных } \\
\text { средств после } \\
\text { расторжения } \\
\text { договора }\end{array}$ & $\begin{array}{l}\text { Остаток денежных средств перечисляется } \\
\text { на другой номинальный счет владельца } \\
\text { счета или выдается бенефициару, либо } \\
\text { перечисляется по указанию бенефициара } \\
\text { на другой счет }\end{array}$ & $\begin{array}{l}\text { Остаток денежных средств перечисляется } \\
\text { бенефициару, однако если оснований для пе- } \\
\text { редачи ему денежных средств не возникло, } \\
\text { то они перечисляются депоненту }\end{array}$ \\
\hline $\begin{array}{l}\text { Арест или спи- } \\
\text { сание денежных } \\
\text { средств по } \\
\text { исполнительным } \\
\text { листам }\end{array}$ & $\begin{array}{l}\text { Допускаются только по обязательствам } \\
\text { бенефициара }\end{array}$ & $\begin{array}{l}\text { Закон не исключает возможности наложения } \\
\text { ареста на денежные средства, находящиеся на } \\
\text { счете-эскроу по исполнительным документам } \\
\text { по обязательствам депонента. В отношении } \\
\text { обязательств бенефициара это невозможно, } \\
\text { так как он до момента получения денежных } \\
\text { средств их владельцем не является }\end{array}$ \\
\hline
\end{tabular}


Оценивая особенности номинального счета и счета-эскроу, их целесообразно сравнивать с аккредитивами и рассматривать в качестве альтернативы способа расчетов.

Инициатором платежа в расчетах по аккредитиву является плательщик. Он составляет в банке заявление на открытие аккредитива, в котором указываются:

- номер и дата аккредитива;

- реквизиты плательщика, банка-эмитента, получателя средств и исполняющего банка;

- сумма и вид аккредитива;

- способ извещения получателя средств об открытии аккредитива;

- полный перечень и точная характеристика документов, предоставляемых получателем средств;

- сроки действия аккредитива и условия предоставления документов, подтверждающих поставку товаров (выполнение работ, оказание услуг), а также требования к их офрормлению;

- условия оплаты;

- ответственность за неисполнение или ненадлежащее исполнение обязательств.

Bce перечисленные пункты становятся условиями действия аккредитива, которые до его заключения покупатель обсуждает с поставщиком (рис. 3).

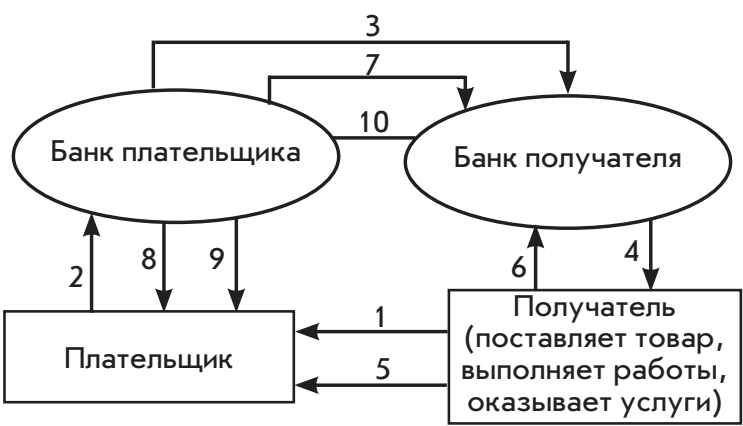

Рис. 3. Схема расчетов

с использованием аккредитива

Составлено по: [10]

Расчеты по аккредитиву включают следующие этапы:

1. Заключение соглашения между покупателем и продавцом товара (или иного актива).

2. Оформление заявления на открытие аккредитива.

3. Сообщение банком эмитентом об открытии аккредитива и его условиях банку продавца (в ряде случаев на этом этапе осуществляется перевод денежных средств в исполняющий банк).

4. Доведение банком продавца соответствующей информации до продавца, получателя средств.
5. Осуществление продавцом поставки товара (или совершение иных действий, предусмотренных договором с покупателем).

6. Предоставление продавцом в банк необходимых документов, свидетельствующих о совершении сделки.

7. Передача банком получателя (после проверки документов) средств в банк продавца для проведения платежа.

8. Извещение банком плательщика своего клиента о фракте проведенного расчета.

Возможны еще 9-й и 10-й этапы в случае, если реально списываемая с аккредитивного счета сумма не меньше той, которая была забронирована первоначально. Если на аккредитивном счете после совершения расчетов остается неиспользованная сумма, а также в случае неисполнения сделки или истечения срока действия аккредитива, клиент (плательщик) вправе обратиться к своему банку о перечислении оставшейся суммы на его расчетный счет (9). В случае использования покрытого аккредитива банк плательщика обращается в исполняющий банк (10) за указанными средствами. После этого можно считать аккредитив закрытым.

Среди всех фрорм безналичных расчетов, используемых сегодня хозяйствующими субъектами, аккредитив получил наименьшее распространение. Основные его недостатки состоят в том, что его применение предполагает наиболее сложный документооборот, длительные сроки, отвлечение средств из оборота, высокие издержки при проведении расчетов. Однако, так же как и номинальный счет и счет-эскроу, аккредитив имеет особый порядок зачисления и использования денежных средств, рассматривается в качестве способа минимизации риска, требует индивидуального подхода, а совершение по нему операций обеспечивает банку получение высокого вознаграждения. Сравнение с номинальным счетом и счетом-эскроу указывает и на некоторые различия (табл. 3).

В результате проведения сравнительного анализа можно выделить общие недостатки, характерные как для механизма организации расчетов с использованием номинального счета и счета-эскроу, так и для расчетов аккредитивами. Это, прежде всего, достаточно высокая стоимость их организации и необходимость отвлечения денежных средств из оборота. В то же время расчеты с использованием номинального счета и счета-эскроу обладают определенными преимуществами, например, более высокой скоростью и оптимизацией механизма движения денежных средств и документов. 
Различия аккредитива, номинального счета и счета-эскроу

\begin{tabular}{|l|l|l|}
\hline \multicolumn{1}{|c|}{ Показатель } & \multicolumn{1}{|c|}{ Аккредитив } & \multicolumn{1}{|c|}{ Номинальный счет и счет-эскроу } \\
\hline Экономическая природа & Форма безналичных расчетов & Способ обеспечения обязательств \\
\hline Документооборот & Более сложный & Менее сложный \\
\hline Скорость расчетов & Медленная & Возрастающая \\
\hline Риски & $\begin{array}{l}\text { В отзывном аккредитиве риски высокие } \\
\text { из-за наличия возможности у плательщика } \\
\text { изменения условий расчетов; в безотзывном } \\
\text { аккредитиве рисков меньше }\end{array}$ & $\begin{array}{l}\text { Риски сокращаются из-за отсут- } \\
\text { ствия возможности у владельца } \\
\text { счета или депонента отзыва } \\
\text { денежных средств }\end{array}$ \\
\hline
\end{tabular}

Современные банки стремятся соответствовать требованиям времени. Постоянно совершенствуя свою деятельность, они предлагают клиентам новые финансовые продукты и услуги. Результатом этого являются показатели сокращения доли наличных расчетов в экономике и роста объемов остатков на корреспондентских счетах банков и средств до востребования.

Важными конкурентными преимуществами банков считаются не только возможности повышения скорости и ликвидности расчетов, но и обеспечение безопасности при проведении платежей.

Номинальные счета и счета-эскроу можно рассматривать в качестве новых фринансовых инструментов, позволяющих снизить риски в расчетах. Основным их достоинством является оптимизация документооборота, а также действий банка и клиентов.

\section{СПИСОК ИСПОЛЬЗОВАННОЙ ЛИТЕРАТУРЫ}

1. Банковские операции : учеб. пособие / под ред. О.И. Лаврушина. - 3-е изд., перераб. - М. : КноРус, 2016. $-380 \mathrm{c}$.

2. Абрамова Е. Н. Специальный банковский счет: правовая природа и классификация / Е. Н. Абрамова // Право и экономика. - 2016. - № 7. - С. 46-54.

3. Галимова Г. А. Электронные деньги как основной инструмент функционирования информационного общества / Г. А. Галимова, З. Р. Абдеева / / Известия Уральского государственного экономического университета. - 2013. - № 2 (46). - С. 68-76.

4. Герасименко М. А. Электронные деньги в современной системе денежного оборота / М. А. Герасименко, Р.Н.Деникаева / / Ученые записки Российской Академии предпринимательства. — 2014. - № 39. C. $18-25$.

5. Механизм оборота электронных денег: теория и практика / С. В. Криворучко, В. А. Лопатин, М. А. Абрамова, И. Е. Шакер. - М. : Русайнс, 2015. - 115 с. $292 \mathrm{c}$.

6. Косой А. М. Платежный оборот: исследование и рекомендации / А. М. Косой. - М. : КноРус, 2012. -

7. Каплина О. С. Электронные деньги как важный инструмент денежного оборота в современной России / О. С. Каплина / / Экономика и предпринимательство. - 2014. - № 6. - С. 222-226.

8. Чижова Э. С. Экономические аспекты регулирования национальной платежной системы / Э. С. Чижова // Новые тенденции в развитии кредита и кредитного рынка : материалы 2-й Междунар. межвуз. конфр. памяти Р. В. Корнеевой. - М. : Изд-во Рос. экон. ун-та им Г. В. Плеханова, 2013. - С. 100-107.

9. Банковское дело : учебник / под ред. Г. Г. Коробовой. - М. : Экономистъ, 2012. - 766 с.

10. Деньги. Кредит. Банки / под ред. А. Ю. Казака, М. С. Марамыгина. — Екатеринбург : АМБ, 2006. - 688 с.

11. Марков М. А. Межбанковский бизнес: цели и принципы осуществления, основные инструменты и ценообразование на них / М. А. Марков / / Управленец. - 2015. - № 2 (54). - С. 46-52.

12. Кузнецов А. Р. Стресс-тестирование в банковском секторе: ликвидность / А. Р. Кузнецов, А. Н. Пыткин / / Известия Уральского государственного экономического университета. - 2015. — № 3 (59). - С. 39-47.

13. Курганский С. А. Изменение институциональных характеристик банковской системы России / С. А. Курганский, Ю. Б. Бубнова // Известия Иркутской государственной экономической академии (Байкальский государственный университет экономики и права). — 2015. - Т. 6, № 3. - DOI: 10.17150/20720904.2015.6(3).1.

14. Самаруха В. И. Экономическая безопасность РФ в современном мире / В. И. Самаруха // Известия вузов. Инвестиции. Строительство. Недвижимость. - 2016. — № 1 (16). - С. 63-67.

15. Маилян Л. М. Проблемы применения норм договоров номинального счета и счета эскроу / Л. М. Маилян / / Образование и право. - 2015. - № 5. - С. 168-174.

16. Эрделевский А. Д. Договор номинального счета и договор счета эскроу / А. Д. Эрделевский // Хозяйство и право. - 2014. - № 11. - С. 85-88.

\section{REFERENCES}

1. Lavrushin O. I. (ed.). Bankovskie operatsii [Banking Operations]. 3rd ed. Moscow, KnoRus Publ., 2016. 380 p.

2. Abramova E. N. Special Bank Account: Legal Nature and Classification. Pravo $i$ ekonomika $=$ Law and Economics, 2016, no. 7, pp. 46-54. (In Russian). 
3. Galimova G. A., Abdeeva Z. R. Electronic money as the main tool of the information society functioning. Izvestiya Uralskogo gosudarstvennogo ekonomicheskogo universiteta = Journal of the Ural State University of Economics, 2013, no. 2 (46), pp. 68-76. (In Russian).

4. Gerasimenko M. A., Denikaeva R. N. Electronic money in the modern system of cash turnover. Uchenye zapiski Rossiiskoi Akademii predprinimatel'stva = Scientific Notes of the Russian Academy of Entrepreneurship, 2014, no. 39, pp. 18-25. (In Russian).

5. Krivoruchko S. V., Lopatin V. A., Abramova M. A., Shaker I. E. Mekhanizm oborota elektronnykh deneg: teoriya i praktika [The Mechanism of Circulation of Electronic Money: Theory and Practice]. Moscow, Rusains Publ., 2015. $115 \mathrm{p}$

6. Kosoi A. M. Platezhnyi oborot: issledovanie irekomendatsii [Payment Operations: Research and Transactions]. Moscow, KnoRus Publ., 2012. 292 p.

7. Kaplina O. S. E-money as an important instrument for the circulation of money in modern Russia. Ekonomika $i$ predprinimatel'stvo = Economics and Entrepreneurship, 2014, no. 6, pp. 222-226. (In Russian).

8. Chizhova E. S. Economic Aspects of Regulation of the National Payment System. Novye tendentsii $v$ razvitii kredita i kreditnogo rynka. Materialy 2-i Mezhdunarodnoi mezhvuzovskoi konferentsii pamyati R. V. Korneevoi [New Tendencies in the Development of Loans and Loan Market. Proceedings of the $2^{\text {nd }}$ International Inter-University Conference in Memory of R.V. Korneeva]. Moscow, Plekhanov Russian University of Economics Publ., 2013, pp. 100-107. (In Russian).

9. Korobova G. G. (ed.). Bankovskoe delo [Banking]. Moscow, Ekonomis Publ., 2012. 766 p.

10. Kazak A. Yu., Maramygin M. S. (eds). Den'gi. Kredit. Banki [Money. Credit. Banks]. Yekaterinburg, AMB Publ., 2006. 688 p.

11. Markov M. A. Interbank business: objectives and principles of implementation, main tools and pricing. Upravlenets $=$ The Manager, 2014, no. 2 (54), pp. 46-52. (In Russian).

12. Kuznetsov A. R., Pytkin A. N. Stress-testing in banking sector: liquidity. Izvestiya Uralskogo gosudarstvennogo ekonomicheskogo universiteta = Journal of the Ural State University of Economics, 2015, no. 3 (59), pp. 3947. (In Russian).

13. Kurgansky S. A., Bubnova Yu. B. Changing institutional characteristics of Russia's banking system. Izvestiya Irkutskoi gosudarstvennoi ekonomicheskoi akademii (Baykalskii gosudarstvennyi universitet ekonomiki i prava) = Izvestiya of Irkutsk State Economics Academy (Baikal State University of Economics and Law), 2015, vol. 6, no. 3. DOI: 10.17150/2072-0904.2015.6(3).1. (In Russian).

14. Samarukha V. I. The Economic Security of the Russian Federation in the Modern World. Izvestiya vuzov. Investitsii. Stroitel' stvo. Nedvizhimost' $=$ Proceedings of Universities. Investments. Construction. Real Estate, 2016, no. 1 (16), pp. 63-67. (In Russian).

15. Mailyan L. M. Problems of application of standards of contracts of the nominal account and escrow account. Obrazovanie i pravo = Education and Law, 2015, no. 5, pp. 168-174. (In Russian).

16. Erdelevskii A. D. Nominal Account Agreement and Escrow Account Agreement. Khozyaistvo i pravo $=$ Economy and Law, 2014, no. 11, pp. 85-88. (In Russian).

\section{Информация об авторах}

Прокофьев Александр Владимирович - кандидат экономических наук, заместитель управляющего фрилиала публичного акционерного общества «ВТБ», 620014, г. Екатеринбург, ул. Маршала Жукова, 5, e-mail: 7004prokofev-av@mail.ru.

Татьянников Василий Аркадьевич - кандидат экономических наук, профессор кафредры финансовых рынков и банковского дела, Уральский государственный экономический университет, 620144, г. Екатеринбург, ул. 8 Марта, 62, e-mail: vat55@mail.ru.

Прокофьева Елена Николаевна - кандидат экономических наук, доцент, доцент кафедры финансовых рынков и банковского дела, Уральский государственный экономический университет, 620144, г. Екатеринбург, ул. 8 Марта, 62, e-mail: 7004prokofev-av@mail.ru.

\section{Для цитирования}

Прокофьев А. В. Новые инструменты безналичных расчетов: специальные банковские счета / А. В. Прокофьев, В. А. Татьянников, Е. Н. Прокофьева // Известия Байкальского государственного университета. - 2017. - Т. 27, № 3. - C. 411-418. DOI: $10.17150 / 2500-2759.2017 .27(3) .411-418$.

\section{Authors}

Alexander V. Prokofiev - PhD in Economics, Deputy Manager of the branch of Public JSC "VTB", 5 Marshal Zhukov St., 620014, Yekaterinburg, Russian Federation, e-mail: 7004prokofev-av@mail.ru.

Vasily A. Tatyannikov - Ph.D. in Economics, Professor, Department of Financial Markets and Banking, Ural State University of Economics, 62 Vosmogo Marta St., 620144, Yekaterinburg, Russian Federation, e-mail:vat55@mail.ru.

Elena N. Prokofieva - PhD in Economics, Associate Professor, Department of Financial Markets and Banking, Ural State University of Economics, 62 Vosmogo Marta St., 620144, Yekaterinburg, Russian Federation, e-mail: 7004prokofev-av@mail.ru.

\section{For Citation}

Prokofiev A. V., Tatyannikov V. A., Prokofieva E. N. New Instruments of Non-Cash Payments: Special Bank Accounts. Izvestiya Baykal'skogo gosudarstvennogo universiteta $=$ Bulletin of Baikal State University, 2017, vol. 27, no. 3, pp. 411-418. DOI: 10.17150/25002759.2017.27(3).411-418. (In Russian). 